\title{
Poder e fidelidade na interpretação
}

\section{Power and Fidelity in Interpreting}

\author{
Christiano Sanches do Valle Silva* \\ "Behind a curtain of professional neutrality, \\ conference interpreters dedicate themselves \\ to their art with the utmost passion." 1
}

\begin{abstract}
Resumo: Este artigo argumenta que, no âmbito de uma discussão multidisciplinar sobre poder e ideologia na prática da interpretação, diferentes tipos de fidelidade são construídos de acordo com influências do meio em que atuam os intérpretes, em interação com os valores que os informam no exercício de seu ofício. Neste trabalho, são abordadas questões de ética e de controle do discurso por parte do intérprete, com base em estudos de caso, colocando em perspectiva os limites de sua atividade e favorecendo o pensamento crítico sobre a profissão e os estudos acadêmicos que a têm como objeto.
\end{abstract}

Palavras-chave: Interpretação; poder; ideologia; fidelidade; neutralidade; agentividade; discurso.

Abstract: This paper defends that, within a multidisciplinary discussion on power and ideology in the practice of interpretation, different kinds of fidelity are established according to the influences of the context in which interpreters carry out their task, always imbued with values and concepts they bring to the scene. Issues of ethics and

\footnotetext{
* Intérprete de conferências e tradutor; docente na Formação de Intérpretes de Conferência da PUC-Rio (Pós-Graduação Lato Sensu). E-mail: christianosanches@gmail.com.

${ }^{1}$ Legenda de foto na página de abertura do site da AlIC (Disponível em: ঝttp:// aiic. net>).
} 
control of discourse by interpreters are also investigated here through case studies, challenging the limits of the interpreters' activity and fostering critical thinking on the profession and the research about it.

Keywords: Interpreting; power; ideology; fidelity; faithfulness; neutrality; agency; discourse.

\section{Introdução}

Ao ler a epígrafe acima, chamou-me a atenção a combinação de duas palavras tão díspares na mesma frase: neutralidade e paixão (neutrality e passion).

Enquanto a neutralidade aparece relacionada a um caráter de profissionalismo dos membros da AlIC (Associação Internacional de Intérpretes de Conferência), ou seja, uma neutralidade na postura do profissional, que não revela suas motivações mais íntimas e pessoais; a palavra passion remete, inevitavelmente, a algo de caráter mais emocional, em oposição ao racional.

Percebe-se aí a evidência de um conflito antigo no meio da interpretação: o embate entre a necessidade de ser aceito e conquistar a confiança dos interlocutores, por meio de uma postura profissional que reflita neutralidade, e as influências já tão amplamente discutidas do contexto sócio-político-cultural no qual se dá a atividade do intérprete, esse intermediário que detém, no ato da interpretação, o poder do discurso.

Levando-se em conta tal conflito, a proposta deste artigo é evidenciar como, em situações as mais diversas, o intérprete faz uso de suas capacidades de acordo com interesses próprios, ou escolhas pessoais. Para esse fim, acredito que os casos aqui relatados deverão contribuir para a observação das implicações de poder e fidelidade no exercício da profissão de intérprete. A história está repleta de exemplos interessantes nos quais a atuação desses profissionais foi importante e, muitas vezes, determinante. Citarei apenas 
três neste artigo, mas outros existem que podem em muito contribuir com essa observação².

Parto do princípio de que, no meio acadêmico, no âmbito de uma epistemologia pós-moderna hoje praticamente hegemônica, a neutralidade como valor em si não é possível, sendo o indivíduo afetado em suas ações e escolhas por toda a gama de variáveis de sua educação, vivência social e afetiva, valores pessoais, políticos, etc., aqui identificados como sua ideologia. Na tradução e na interpretação, situações que ensejam escolhas linguísticas e encontros entre culturas, seria difícil hoje em dia conceber que tais escolhas seriam feitas de maneira totalmente alheia ao meio no qual se inserem.

Contudo, não é difícil compreender porque uma associação de âmbito internacional, e que esteve à frente do estabelecimento de normas fundamentais de condições e qualidade de trabalho, ainda se apresente colocando ênfase na tão questionada neutralidade, deixando implícita a crença na sua possibilidade teórica, como vemos na epígrafe acima. Assim como o sigilo, princípio básico presente no código de ética da AllC, a neutralidade está diretamente ligada à confiabilidade dos profissionais a ela afiliados, e a confiança só se constrói quando sentimos que aquele ou aquela que media nossas palavras não procura imprimir suas próprias ideias em nosso discurso, não interfere de maneira consciente no que o discurso original traz em si, a não ser para realizar as necessárias adequações linguísticas.

Muitas vezes, associa-se à tradução/interpretação a ideia de traição, em decorrência ou da crença na impossibilidade de realizar satisfatoriamente tais atividades - o famoso adágio "traduttore, traditore" é repetido até hoje ou da desconfiança de que 0 tradutor/intérprete pode não ser

2 Para uma abordagem mais completa do tema, com inclusão de outros casos, consultar a dissertação de mestrado do autor deste artigo: SILVA, C. \& MARTINS, M., 2013. 
suficientemente "fiel" ao texto de origem, seja por incompetência, seja por uma postura deliberada de não neutralidade.

Se adotarmos a concepção de tradução de autores como VenUTI (1995), para o qual traduzir é, necessariamente, transformar, entenderemos que determinadas alterações são inevitáveis, sendo até mesmo uma condição própria da tradução de forma geral, pois um discurso ou texto original traduzido não poderá ser o mesmo, uma vez que já será reproduzido em outro idioma.

As alterações às quais se refere VENUTI são, portanto, naturais à passagem de um idioma a outro, não implicando uma "traição" do original no sentido estrito do termo ou uma postura tendenciosa. No entanto, o discurso de valorização da neutralidade, como postura ética do profissional tradutor ou intérprete que não interfere no sentido do texto ou discurso de origem, está inscrito profundamente em nossa mentalidade, mesmo quando se questiona a existência da neutralidade epistemológica nas relações interpessoais e profissionais.

Em entrevista publicada no periódico Cultus em 2008, Mona BAKER e Andrew CHESTERMAn resumem bem a questão ao mencionar a necessária suspensão da crença na impossibilidade da neutralidade absoluta para que funcione a relação entre tradutores/ intérpretes, de um lado, e seus clientes e a sociedade como um todo, de outro. BAKER ressalta ainda a discrepância que existe entre as expectativas do público em geral e a prática profissional da tradução, uma expectativa que a própria profissão e a academia ajudam a sustentar, segundo ela.

Evidentemente, como atitude durante a interpretação, é possível sim assumir uma postura neutra, que, até onde o profissional é capaz de controlar suas escolhas, permite às partes comunicantes dispor de uma tradução fiel segundo o senso comum, ou seja, o mais próxima possível do que está sendo dito, e de como está sendo dito. Interessa-me aqui perceber até que ponto essa neutralidade e essa fidelidade são realmente possíveis ou desejadas. 
Foi como intérprete atuante no mercado, e partindo da observação de que o material acadêmico e o discurso profissional não estavam totalmente sintonizados com relação à possibilidade de neutralidade e ao poder inerente ao ofício do intérprete, que considerei interessante abordar a questão da ideologia e do poder e sua verificação no ato da interpretação, uma atividade que existe há milênios, mas que só recentemente passou a ser associada a um meio profissional que demanda qualificação específica (PöCHHACKER 2004).

Além disso, o interesse crescente pelo modo de interpretação comunitária engendrou uma ênfase cada vez maior no "intérprete como agente ativo de comunicação em uma variedade de contextos" (DIRIKER 2009: 56). Diversos autores passaram a observar a atuação do intérprete de conferências como algo que ocorre em contextos passíveis de uma análise sociológica, considerando a interpretação como um sistema de comunicação influenciado por fatores linguísticos e extralinguísticos e chamando a atenção para a maneira como o meio molda as elocuções (DIRIKER 2009).

Sintonizado com o movimento já observado nos Estudos da Tradução, Michael CRONIN (2002) lançou um apelo por uma "virada cultural" também nos Estudos da Interpretação, sublinhando a relação íntima entre esta atividade e o poder. 0 autor salienta como o papel dos intérpretes foi, ao longo da história, fundamentalmente determinado por sua posição numa hierarquia de poder e afirma que o "problema central da tradução em geral e da interpretação em particular é o problema do controle" (CRONIN 2002: 392). Citando R. Bruce W. Anderson e seu artigo "Perspectives on the Role of the Interpreter", de 1976, CRONIN (2002) associa a posição intermediária do intérprete à sua capacidade de controlar recursos escassos, que seriam, no caso da interpretação, ligados ao domínio dos idiomas em questão.

A título de ilustração, CRONIN (2002) menciona a já conhecida história de Doña Marina, a intérprete de Cortés, conhecedora dos idiomas maia, asteca e espanhol, considerada por alguns comentadores mexicanos do período pós-independência como figura monstruosa, "mãe de uma raça de 
mestiços e traidores" (p. 392), e, por outros, um exemplo de flexibilidade e recursos, um "arauto das sociedades culturalmente híbridas do futuro" ( $p$. 392).

No ato da comunicação mediada, o que se negocia é o discurso, ou discursos, das diferentes partes. Para Pierre BouRdieu (2003), relações de comunicação são sempre relações de poder, e o discurso, como afirma Foucault (2011), é "aquilo por que, pelo que se luta, o poder do qual nos queremos apropriar" (p. 10). Configura-se assim uma situação na qual o intermediário, intérprete/tradutor, se vê na posição de um dos agentes capazes de exercer o poder do discurso.

E como pode o intérprete exercer, ou experimentar o poder do qual é investido quando da interpretação? De que maneiras manifesta-se tal poder? Como se pode falar de neutralidade nesse contexto? Quais as discussões possíveis ao redor desse tema?

Uma maneira de se observar como 0 poder se manifesta na interpretação é através de sua associação direta com a fidelidade. Não necessariamente a fidelidade ao texto, mas a uma ou mais das partes que se utilizam dos serviços do intérprete, como veremos a seguir. É na tentativa de responder às perguntas acima que apresento aqui uma leitura de casos de interpretação na qual o viés da fidelidade é o fio condutor.

\section{Alguns casos}

\section{1 Os dragomanos}

O primeiro caso aqui abordado baseia-se nos trabalhos de BelLos (2011a) e LEWIS (2004).

Nas páginas 126 a 128 de seu livro, Bellos (2011a) expõe o ambiente de tradução e interpretação que predominava no antigo Império Otomano, já 
brevemente mencionado na introdução deste trabalho. Devido à expansão imperial, a necessidade de comunicação entre povos com idiomas diferentes se impôs. Entre inúmeros intérpretes e tradutores desconhecidos, despontavam aqueles que desempenhavam funções na diplomacia da época, servindo de intermediários entre autoridades de distintas origens. Estes eram conhecidos como dragomanos e chegaram a formar uma rede de intérpretes/ tradutores de transmissão hereditária, como era costume naquele tempo (Bellos 2011a).

$\mathrm{Na}$ complexa estrutura de poderes do antigo Império Otomano, o sistema de interpretação tampouco era simples. O governo local utilizava os serviços de um grupo específico de intérpretes súditos do Império, enquanto as embaixadas e consulados estrangeiros obtinham o mesmo serviço de outro grupo de intérpretes de menor prestígio aos olhos das autoridades locais. Esses "grupos" chegaram a formar verdadeiras dinastias de intérpretes e tradutores a serviço de um ou outro Iado, Império Otomano ou autoridades estrangeiras (LEWIS 2004).

Uma profunda diferença cultural permeava essas relações, e com frequência os ocidentais relatavam como grande parte do material traduzido não passava de invenções dos intérpretes. Isso porque, na tradição oral da região, longos trechos de fala eram dedicados a fórmulas de cortesia envolvendo demonstrações de respeito e subserviência aos representantes orientais (Bellos 2011a). Mais do que isso, os intérpretes locais, mesmo não trabalhando oficialmente para a corte, conheciam muito bem seu funcionamento e sabiam o risco que corriam se desagradassem a alguma autoridade imperial, o que seria muito mais grave do que desagradar a um visitante ocasional, ou a uma autoridade estrangeira.

Segundo LeWIS (2004), desde o princípio, documentos diplomáticos britânicos incluem reclamações quanto ao serviço prestado pelos intérpretes de turco, o idioma falado no Império. Muitos mencionam o fato de que mensagens desagradáveis às autoridades otomanas eram veiculadas de 
maneira mais branda. Contudo, a principal reclamação estava relacionada à lealdade dos intérpretes e tradutores, que eram capazes de vender informações e segredos aos quais tinham acesso para quem pagasse o maior valor. A maioria dos intérpretes de embaixadas estrangeiras fazia parte de um mesmo grupo identitário de dragomanos e era comum que trocassem informações entre si.

Outra acusação frequente e comprovada pela documentação histórica é que os intérpretes "tinham medo - medo demais para realizar seu trabalho adequadamente" (LEWIS 2004: 25), pois eram súditos do sultão, sem nenhum prestígio ou imunidade, não sendo tampouco originários da Europa ocidental e, portanto, não contando com o apoio das embaixadas estrangeiras. LEWIS oferece um exemplo de petição escrita por um dragomano a um oficial do exército turco que ilustra o tipo de linguagem utilizada nas comunicações entre intérpretes locais e autoridades otomanas, deixando claro o motivo de preocupação das autoridades estrangeiras com a transmissão de mensagens oficiais por esse meio. 0 trecho abaixo foi retirado pelo autor dos National Archives britânicos:

Esta é a petição do dragomano ao Aga dos janízaros: Tendo baixado minha cabeça em submissão e esfregado minha sobrancelha servil, em total humildade e completa abjeção e súplica, na benfazeja poeira sob os pés de meu benfeitor poderoso, gracioso, condescendente, compassivo e misericordioso, meu mestre mais generoso e magnânimo, rogo que o incomparável e todo-poderoso provedor de remédios abençoe sua eminente pessoa, o benefício extremo, proteja meu benfeitor das vicissitudes e aflições do tempo, prolongue os dias de sua vida, sua grandeza e seu esplendor, e perpetue a sombra de sua piedade e misericórdia sobre este escravo (LEWIS 2004: 26). ${ }^{3}$

\footnotetext{
${ }^{3}$ A tradução deste e de outros trechos aqui citados é de minha autoria.
} 
Aos olhos das autoridades imperiais, os intérpretes já eram suspeitos pelo simples fato de trabalharem para uma embaixada estrangeira. Para os dragomanos, "adicionar alguns parágrafos de devoção eterna não era má tradução. Era um seguro de vida" (BelLos 2011a 128).

0 exemplo dos dragomanos permite-nos observar questões ideológicas e de poder pelo viés da fidelidade, que era de suma importância para os intérpretes otomanos, mas não no mesmo sentido que predomina no senso comum, de fidelidade ao texto fonte. Os dragomanos precisavam provar que eram fiéis ao sultão ou à autoridade local com a qual estivessem interagindo (Bellos 2011a).

Da mesma maneira, podemos examinar este caso tomando por base a confiança, associada por Bellos (2011a) à força de uma elocução. Se essa força está intimamente ligada à identidade do falante, não pode, portanto, ser transmitida por outro falante que não o original. Segundo o autor, essa regra fundamental deve ser suspensa para que possa existir a interpretação, pois exige que o ouvinte considere as palavras do intérprete como tendo sido ditas pelo falante de um idioma estrangeiro. Por isso, ainda de acordo com BelLos, a tradução oral, em um mundo sem escrita, baseia-se numa ficção. Diz ele:

\footnotetext{
O primeiro grande avanço na história da tradução deve ter ocorrido quando duas comunidades chegaram a um acordo de que a elocução do tradutor deveria ser tomada como tendo a mesma força da elocução imediatamente anterior do principal (BELLOS 2011a: 121).
}

Ou seja, para que a cena da interpretação se estabeleça é preciso que exista um acordo tácito e uma confiança de que a mensagem original não será perdida ou manipulada no processo. Nessa configuração, estabelecem-se relações de poder momentâneas que configuram o agir de cada participante da cena.

Para BeLLos, 
a confiança nunca é conferida sem reservas. Para que sejam conduzidas negociações entre duas comunidades que falem idiomas mutuamente incompreensíveis, o usuário de interpretação fica nas mãos do intérprete, assim como o intérprete serve apenas um mestre e está a ele submetido. Uma situação fadada a gerar ansiedade, suspeita e desconfiança (BELLOs 2011a: 122).

Mesmo hoje em dia, o medo de um desempenho imperfeito ou enganoso por parte do intérprete afeta os protocolos de reuniões privadas entre chefes de estado. Além disso, devido a questões de soberania que permeiam as relações políticas internacionais, um chefe de estado costuma se dirigir a outro no idioma de seu país, enfatizando a ideia de que seu idioma não é menos importante do que outros.

Cada lado traz seu próprio intérprete. Quando o primeiro-ministro britânico tem uma conversa privada com o presidente francês, a pessoa contratada pelo governo de Sua Majestade fala em francês em nome do primeiro ministro e, da mesma forma, o intérprete francês responde com as palavras do presidente em inglês. Essa tradução oral de discursos em duas vias, do idioma materno para um idioma estrangeiro, é raramente vista em público. Esse tipo de arranjo remete diretamente à questão da confiança na interpretação (BELLOS 2011a: 122).

Nesse contexto específico, fica evidenciada a importância das relações implícitas estabelecidas entre os participantes da situação interpretada. É de acordo com essa rede invisível de forças que o discurso é pensado e transmitido, pois cada palavra tem repercussões que vão além do instante de sua elocução.

Diferenciais de cultura, expectativa dos interlocutores, comprometimento cultural e ideológico do intérprete e até mesmo 0 medo, na forma de possíveis ameaças à integridade física, são todos elementos a serem considerados. 
Se pensarmos do nível mais individual ao mais geral, vemos como decisões tomadas por um intérprete, que pensa basicamente em se preservar e conquistar a estima das autoridades locais, afetam diretamente a comunicação entre essas mesmas autoridades e os representantes de outros países ou territórios. Dessa forma, aquela decisão de cunho pessoal acaba por moldar o relacionamento político e comercial entre as instâncias nacionais, perpetuando, ao mesmo tempo, a cadeia de hierarquias local e internacional, ao limitar sua expressão e fixar seus limites.

Nessa visão de uma teia de relações de força, a submissão ao poder central local leva o elo aparentemente mais frágil da cadeia, o intérprete, a ter uma repercussão significativa na comunicação entre elos em teoria mais fortes, as autoridades de diferentes nações.

Podemos pensar que, na época dos dragomanos, as relações de poder eram mais explícitas, ou ao menos o eram as ameaças que pairavam sobre os "infiéis"; contudo, mesmo hoje em dia, ainda se pode encontrar esse tipo de encadeamento cíclico que perpetua poderes institucionais, do nível mais local ao menos local.

\subsection{0 intérprete da FUNAI}

Em matéria da revista Veja, em 09 de novembro de 2011, temos o caso de uma equipe de televisão australiana que veio ao Brasil rodar um documentário sobre uma tribo que ainda hoje vive isolada na Amazônia, os suruuarrás.

Para chegar até a aldeia, a equipe de TV entrou em contato com a Fundação Nacional do Índio (FUNAI), que cobrou sete mil dólares pela visita alegando que o dinheiro era para os índios - e designou um intérprete para acompanhá-los. 
Durante a visita à aldeia, o único elo de comunicação entre australianos e indígenas era 0 intérprete indicado pela FUNAI. Foi somente semanas mais tarde, em contato com missionários que prestavam auxílio à tribo, que os jornalistas descobriram que haviam sido enganados. Ao ouvir e ver as gravações, os missionários, capazes de entender a língua dos suruuarrás, revelaram aos perplexos australianos que o intérprete havia omitido uma série de informações passadas pelos índios e ainda aproveitara o ensejo para aterrorizá-los - aos suruuarrás - com uma suposta mensagem de deputados instalados em Brasília.

As omissões do intérprete ocorriam sempre que os índios passavam informações sobre sua cultura que poderiam macular a imagem do "bom selvagem" sustentada pela FUNAl, como, por exemplo, quando falavam sobre a tradição de matar crianças que nascem com problemas físicos congênitos e gêmeos. Toda a atuação do intérprete visava também convencer os australianos de que a tribo estava muito feliz vivendo naquele lugar e naquelas condições.

Essa versão dos fatos fez mais sentido para os jornalistas, que chegaram a desconfiar que algo pudesse estar errado, ao observar os índios pedindo roupas e alimentos, e sinalizando que passavam frio, sem que isso fosse traduzido.

Segundo o texto da reportagem da revista Veja, não é do interesse da FUNAI que os índios mudem de status, mas sim que permaneçam na selva em condições precárias, no que um dos jornalistas australianos chamou de "museu antropológico vivo" (ELER 2011: 98).

Outro fato interessante na matéria é seu título: "O SAP da FUNAI". Vemos aí uma associação do ato de interpretar ao dispositivo que permite, automaticamente, mudar o idioma de algum programa que assistimos na televisão. É interessante observar a ideia de automatismo associado ao ato de interpretar/traduzir, que surge, neste caso, em contraste agudo com a 
postura do intérprete, responsável pela total adulteração da fala original dos suruuarrás.

Discussões políticas à parte - a questão indígena no Brasil está longe de ser um consenso e de encontrar soluções - o fato é que o poder detido pelo intérprete nessa situação era tal, sua agenda política e filiação ideológica tão claras, que sua atuação mal pode ser classificada como interpretação, pois foi uma recriação da realidade em prol de interesses específicos.

Ao que tudo indica, o intérprete da FUNAl agiu para preservar os interesses da instituição à qual está vinculado, perpetuando a ocultação de uma realidade. Agiu também a favor da preservação de uma ideologia sustentada pela agência governamental em seu tratamento das questões indígenas no país, procurando exportar uma imagem construída artificialmente e mantida à custa do próprio bem estar da tribo.

Como ocorre em situações nas quais as partes comunicantes não possuem nenhum conhecimento do idioma do outro, a dependência do intérprete era total. Tudo o que era dito pelos suruuarrás era reelaborado pelo intérprete, e o mesmo ocorria quando os australianos tentavam comunicar algo aos indígenas.

Se retomarmos o que disse FoucAult (2011), em sua visão de uma sociedade na qual o discurso é controlado e exerce um papel central em mecanismos de exclusão e de interdição, temos então um exemplo contundente de exclusão por meio da impossibilidade de comunicação, como se a fala dos suruuarrás tivesse sido silenciada, seu direito de expressão negado. Como diz o autor (2011):

[...] o discurso não é simplesmente aquilo que traduz as lutas ou os sistemas de dominação, mas aquilo por que, pelo que se luta, 0 poder do qual nos queremos apropriar (FoucAult 2011: 10). 
O discurso é fundamental. A impossibilidade de usá-lo adequadamente representa, no caso dos suruuarrás, um aprisionamento na condição imposta por aquele que detém o poder do discurso, seja este o intérprete, a FUNAI ou o governo federal.

A fidelidade do intérprete, neste caso, não foi nem às palavras, nem ao sentido do que era dito. Ele também não foi fiel a seus contratantes, os jornalistas australianos. Sua fidelidade foi à FUNAI, que o indicou, e, muito provavelmente, aos benefícios obtidos na relação com esta.

Saber onde 0 intérprete investirá sua fidelidade é praticamente impossível. É preciso acreditar que ele ou ela agirá de maneira profissional e de acordo com as normas, por exemplo, de associações de classe, respeitando o máximo possível o conteúdo do original. Mas o que ocorre quando é preciso recorrer a intérpretes não profissionais?

No caso que acaba de ser apresentado, a mensagem dos suruuarrás só chegava aos ouvidos dos australianos - ou aos leitores da Veja - por meio de dois possíveis veículos: o intérprete da FUNAI e os missionários cristãos. Por mais que os próprios jornalistas tenham, de alguma forma, percebido a pertinência daquilo que Ihes foi transmitido pelos religiosos, é preciso lembrar que nenhum dos participantes desse episódio agiu de maneira profissional. 0 primeiro, apesar de se apresentar como intérprete, parece ter adulterado completamente a fala dos indígenas, pelos supostos motivos já mencionados, indo contra tudo o que é pregado pelas associações profissionais. Os segundos, por sua vez, além de não serem intérpretes e não se apresentarem como tais, não poderiam ser considerados isentos, na medida em que seu obj etivo maior

está ligado ao papel de missionários que exercem. Como veremos no caso a seguir, depender de pessoas sem qualificação profissional para a realização de uma interpretação/tradução não é uma circunstância tão improvável quanto pode parecer. 


\section{3 Interpretação em idioma fula no caso DSK}

O tipo de situação vivido pelos jornalistas australianos pode muito facilmente ocorrer quando os dois idiomas em interação são mutuamente incompreensíveis e, portanto, quando a dependência no intérprete é extrema.

Outra matéria, publicada no Wall Street J ournal e assinada por David Bellos (2011b), relata a dificuldade que a procuradoria do distrito de Nova lorque teve em encontrar um intérprete de fula, língua falada por um grupo étnico de países da África Ocidental e usada numa conversa telefônica, que havia sido gravada e integrava as provas do processo de acusação de Dominique Strauss Khan (DSK). Tratava-se de uma conversa entre Nafissatou Diallo - que acusava DSK de tê-la violado, num processo extremamente midiatizado - e uma amiga sua vivendo no Arizona.

A procuradoria de Nova lorque precisou de semanas somente para identificar de que idioma se tratava. Em seguida, teve grande dificuldade em encontrar um intérprete qualificado para decifrar o telefonema. Acabou tendo que se contentar com um falante de fula sem nenhum vínculo formal com a atividade de tradutor ou de intérprete, a despeito das rigorosas normas profissionais exigidas pela corte de Nova lorque.

$\mathrm{O}$ autor do artigo menciona ainda um fato que considerou cômico. Em determinado momento, o advogado de defesa alegou que havia um erro na tradução do telefonema. Como poderia ele estar seguro disso se também dependeu totalmente de um intérprete não profissional?

A completa incomunicabilidade entre os falantes de inglês e de fula tornou o papel dos intérpretes ainda mais fundamental e crítico para o desenrolar dos procedimentos jurídicos, mas o fato daqueles não serem profissionais certificados fez com que sua credibilidade fosse colocada em questão e transformou a situação numa conversa de surdos.

A relevância da interpretação nesse caso vem à tona com muita clareza. Assim como no caso dos suruuarrás, o poder de transmitir a 
mensagem estava totalmente nas mãos dos intérpretes e, em ambos os casos, até mesmo a contestação da primeira tradução pode ser questionada, uma vez que é preciso confiar cegamente na palavra daqueles que alegam compreender o idioma original, mas que não possuem nenhuma credencial que justifique sua credibilidade.

Em tal situação, voltamos a nos perguntar: qual o objeto da fidelidade do intérprete? Seria ele fiel às palavras, ao sentido ou àqueles que 0 contrataram? Mas existe ainda outro elemento de suma importância no caso DSK: a fidelidade a uma cultura, certamente muito diferente da norteamericana. Explico: Nafissatou Diallo, assim como o falante de fula utilizado como intérprete, é originária de um país da costa oeste africana, a República da Guiné, e o idioma fula é apenas uma das oito línguas nacionais, além dos idiomas falados por numerosos grupos étnicos e do francês, língua oficial da ex-colônia da França, que decretou sua independência em 1958. A população da Guiné é composta por $85 \%$ de muçulmanos, $8 \%$ de cristãos e conta ainda com $7 \%$ de praticantes de crenças locais ${ }^{4}$.

0 julgamento em questão envolvia uma alta autoridade de nacionalidade francesa, Dominique Strauss-Kahn, então diretor do Fundo Monetário Internacional e cogitado como possível candidato à presidência da França, e uma arrumadeira de hotel, Diallo, imigrante oriunda da Guiné, residindo nos Estados Unidos. 0 equilíbrio de forças parece indicar claramente quem era o lado menos privilegiado e quem poderia contar com mais recursos para enfrentar tal processo.

Sem entrar no mérito do julgamento em si, interessa-nos pensar a postura do intérprete convocado para atuar na tradução dos telefonemas gravados em fula. Qual seria, por exemplo, sua visão pessoal dos acontecimentos? Estaria ele imbuído de algum sentimento com relação à sua

\footnotetext{
${ }^{4}$ Disponível em: http:// www. nationsonline. org/ oneworld/ guinea. htm.
} 
SILVA, C. S. do V - Poder e fidelidade na tradução

conterrânea, seja a favor ou contra? Em sua cultura, seriam o comportamento de Diallo e sua exposição na mídia considerados uma aberração, mesmo que ela fosse considerada inocente pela corte de Nova lorque? Teria ele uma empatia instantânea por alguém vindo, como ele, de tão longe? Não temos a resposta a tais perguntas, mas podemos, como sugere Bellos (2011b), questionar a atuação do intérprete não profissional que - vale lembrar desconhece os códigos de ética da profissão e é, de uma maneira ou de outra, informado por suas próprias crenças e valores.

Evidentemente, os códigos de ética e a filiação a alguma instituição ou associação de profissionais não são, por si sós, garantia da qualidade da interpretação ou da neutralidade/imparcialidade do intérprete, mas são o que há de mais próximo a essa garantia, uma vez que o profissional assume 0 compromisso de se ater aos valores expressos em um código e passa a fazer parte de uma comunidade de profissionais que zelam pelo nome de sua associação.

Cabe ressaltar que existem muitas controvérsias mesmo no meio profissional da tradução/interpretação, com grupos como ECOS, Tlaxcala e Babels organizados em torno de uma proposta ativista, que estaria desvinculada dos valores hegemônicos representados, por exemplo, pela AllC, a Associação Internacional de Intérpretes de Conferência.

PöCHHACKER (2006) levanta essa questão e discute o posicionamento do grupo Babels, criado com o intuito de organizar intérpretes voluntários para trabalharem nos Fóruns Sociais, partindo do princípio que "para interpretar um debate de cunho político e social de maneira fiel e excelente o intérprete deve estar profundamente convencido da Causa e comprometido com ela" ( $p$. 12), afirmativa à qual o autor se opõe. Segundo ele, a própria ideia de ter um evento interpretado apenas por voluntários ativistas, imbuídos de uma mesma ideologia, faz com que dificilmente estes sejam imparciais ao se depararem com visões conflitantes ou opostas a seus próprios valores, enquanto intérpretes com um compromisso declaradamente profissional poderiam, ao 
menos, procurar assumir a necessária distância para veicular a mensagem sem tanta interferência.

O ponto crítico aqui está ligado à possibilidade da imparcialidade, à fidelidade ao sentido do discurso traduzido, ao profissionalismo como atitude de respeito ao que está sendo dito, independentemente de filiações políticas ou ideológicas. A despeito dos conflitos existentes na área, para PöCHHACKER

parece haver um consenso de que intérpretes de conferência sejam membros da AllC ou voluntários da Babels - trabalharão invariavelmente no interior de uma ideologia, seja ela qual for. 0 que é fortemente contestado, contudo, são as implicações desse embasamento ideológico para o desempenho de um intérprete (PÖCHHACKER 2006: 12).

Assumindo um posicionamento mais crítico com relação aos valores tidos como hegemônicos, e especialmente em contraste com 0 posicionamento da AIIC, J esus de Manuel J EREZ (2007), intérprete profissional e docente na Universidade de Granada, na Espanha, além de membro das organizações Ecos e Babels, defende uma mudança de postura tanto profissional quanto acadêmica que permita a formação de "uma nova geração de intérpretes cidadãos" (p. 326).

J EREZ (2007) questiona as diferenças de status existentes entre as várias modalidades da profissão de intérprete, como entre interpretação de conferências e interpretação comunitária, procurando identificar os pontos que reforçam visões hegemônicas associadas ao que ele chama de centros do poder - o parlamento europeu, a ONU, e outras instituições do gênero - e aqueles que enfraquecem o papel social do intérprete e sua atuação. 0 autor sugere que uma reflexão já existente no meio da interpretação seja aprofundada, com efeitos que permeiem desde a formação acadêmica dos intérpretes até toda a gama de valores utilizados pela AllC na determinação dos melhores critérios de atuação profissional, e convoca, para tal, a 
participação de "instituições e coletivos sociais, organizados ou não, sejam usuários diretos da interpretação, atuais ou potenciais, ou usuários indiretos" (p. 335), uma vez que o conjunto de ideias, conhecimentos e valores "promovido ou obstaculizado pelos intérpretes afeta toda a sociedade" ( $p$. 335).

A inclusão de idiomas periféricos nos quadros de intérpretes de associações e escolas de formação profissional é um dos efeitos práticos que J EREZ (2007) pretende obter como resultado de uma mudança de paradigma que permita maior inclusão social. Como o autor observa, apesar de a AllC afirmar em sua página que seu quadro de associados é capaz de cobrir qualquer combinação linguística, inúmeros idiomas simplesmente não estão representados ou são oferecidos de maneira bastante limitada, sendo mais presentes as línguas de países colonizadores.

Como vimos, mesmo entre aqueles acostumados a lidar com a interpretação de maneira mais cotidiana existem divergências e conflitos em torno de questões de ética, de ideologia, de fidelidade à palavra, ao sentido, ao contratante, etc. 0 que dizer então de alguém que não é intérprete nem tradutor e que foi chamado para cumprir tal função diante de um tribunal, envolvendo um idioma para o qual a competência dos outros atores implicados é nula. Como não questionar a validade da tradução? E como garantir sua qualidade?

\section{Considerações finais}

Espero ter conseguido, com os casos examinados acima, oferecer uma amostra, mesmo que parcial, de situações contundentes nas quais a interpretação pode ser claramente observada do ponto de vista de sua apropriação do discurso e de sua relevância ao pensarmos nas implicações 
ideológicas e de poder ligadas ao ato de interpretar. Da mesma forma, os contextos nos quais a interpretação foi retratada nos oferecem um vislumbre de como ela se insere numa rede maior de acontecimentos e, portanto, de troca de informações e geração de conhecimento e ações.

Acredito que o termo neutralidade, ao ser usado no âmbito da profissão de intérprete, não implica uma anulação total do profissional como portador de suas próprias crenças e pressupostos, mas sugere que se utilize a neutralidade como um ideal, por mais inatingível que seja, auxiliando 0 intérprete e o tradutor a selecionar com mais rigor e cuidado as interferências inevitáveis que deverá sofrer o texto-fonte ao ser traduzido.

Desde a Antiguidade, como vimos com o caso dos dragomanos, o tema da fidelidade e confiabilidade dos intérpretes está presente de maneira bastante forte, e, se às vezes não são tão explícitas as ameaças que pairam sobre sua atuação, ao menos não em contextos de conferências, os vínculos com instituições e o pertencimento a determinadas estruturas ideológicas e de poder continuam presentes e atuantes.

Existem casos, não mencionados neste artigo, em que a intervenção deliberada do intérprete é bem-vinda, suscitando questionamentos que ainda não encontraram resposta, como por exemplo: até onde o intérprete respeita o sentido do original em tais circunstâncias? Como determinar a partir de que momento a fidelidade à fala original deixa de ser prioridade? Existiria uma "hierarquia de fidelidades" a ser considerada em cada circunstância (palavra, sentido, contexto, etc.)? Essa é, sem dúvida, uma maneira de o intérprete exercer o poder sobre o discurso que interpreta, mas o que deve ser levado em conta, o que deve ser ensinado e aprendido, para que tal exercício de poder ocorra apenas quando necessário e de forma coerente com os valores da profissão?

Às vezes, o poder que 0 intérprete detém leva-o a apropriar-se do discurso em benefício próprio. O intérprete encarregado pela FUNAI da interpretação entre índios suruuarrás e jornalistas australianos possuía, 
certamente, uma agenda previamente acordada com a instituição que 0 indicou e, literalmente, roubou o direito de expressão dos indígenas, mantendo-os isolados e oprimidos em sua não comunicabilidade. A impossibilidade de usar seu próprio discurso colocou os suruuarrás nas mãos de um intérprete cuja fidelidade, aparentemente, não era nem às falas originais, nem a seus contratantes australianos, mas aos benefícios obtidos em sua relação com a FUNAI.

Em outro contexto, perguntas sobre a fidelidade do intérprete são suscitadas quando alguém externo à profissão é contratado para traduzir telefonemas em idioma fula usados no processo Diallo-DSK. Entram em jogo, neste caso, a filiação cultural do intérprete ocasional e sua não adesão a algum código de ética profissional. Contudo, os próprios códigos de ética não representam em si uma garantia absoluta e existem, dentro do meio da interpretação profissional, divergências e discussões de cunho ideológico que se fortaleceram nos últimos anos. A oposição entre Babels e AllC, comentada por PöCHHACKer (2006), é um retrato do comprometimento ideológico que permeia a área da interpretação e da tradução, gerando controvérsias e a necessidade de se aprofundarem mais os estudos sobre as consequências do uso político da tradução/ interpretação.

Além disso, a observação de casos mais extremos pode ser útil quando aplicada à variedade de situações nas quais atua o intérprete. Pode ainda, acima de tudo, auxiliar na determinação dos níveis de formação e informação adequados para a realização de escolhas por parte do profissional. Decorre daí a relevância do tema aqui abordado para os Estudos da Interpretação e as escolas de formação de intérpretes. Espero que este artigo contribua, mesmo que parcialmente, para o aprofundamento desse tipo de questão. 


\section{Referências bibliográficas}

Anderson, R.; Bruce W. Perspectives on the role of interpreter. In: PöCHHACKer, F. e SHLESINGER, M. The Interpreting Studies Reader. London and New York: Routledge, 2002. p. 208-217.

BAKER, M. Narratives of terrorism and security: 'accurate' translations, suspicious frames. Critical studies on terrorism, v.3, n.3, p. 347-364, 2010.

. Ethics of Renarration: Mona Baker is interviewed by Andrew Chesterman. CULTUS, v.1, n.1, p. 10-33, 2008.

BARSKY, R. F. The Interpreter as Intercultural Agent in Convention Refugee Hearings. The Translator. Vol. 2, n. 1, 1996, p. 45-63.

BELLOS, D. Is that a fish in your ear? Translation and the meaning of everything. London: Penguin Books, 2011 a.

. Does J ustice Lose Something in Translation? The Wall Street

Journal, 5 de set. de 2011b. Disponível em: বttp:/ / blogs. wsj .com/ speakeasy/ 2011/ 09/ 05/ david-bellos-we-need-tounderstand-the-difficulty-of-translation/ >. Acesso em: 28/ 06/ 2012.

Blommaert, J. Language, Ideologies and Power. Palestra proferida na International Sociology Conference, Durban, 27 J ulho de 2006.

BouRdieu, P. O Poder Simbólico. Rio de J aneiro: Bertrand Brasil, 2003.

CALZADA-PÉREZ, M. Transitivity in Translation. The Interdependence of Texture and Context. A contrastive Study of Original and Translated Speeches in English and Spanish from de European Parliament. Tese de doutorado não publicada, Edinburgh, Universidade de Heriot-Watt, 1997.

Chabry, A.; Chabry L. Le Pouvoir dans tous ses États: pour une nouvelle science politique. Paris: Imago, 2003.

CRONIN, M. The empire talks back: Orality, heteronomy and the cultural turn in interpreting studies. In: PöCHHACKER, F.; SHLESINGER, M. (Orgs.). The Interpreting Studies Reader. London and New York: Routledge, 2002. p. 387-397. 
DIRIKER, E. Simultaneous Conference Interpreting in the Turkish Electronic and Printed Media: 1988-2003. The Interpreters'Newsletter , v. 12, p 231-243, 2003.

Conference interpreting, sociocultural perspectives. In: BAKER, M. \& SALDANHA, G. (Org.). Routledge Encyclopedia of Translation Studies. Londres e Nova lorque: Routledge, 2009. p. 56-59.

EleR, A. O SAP da FUNAl. In: Revista Veja. Edição 2242, 9 de nov. de 2011. P. 98. Disponível em: বhttp://veja.abril.com.br/acervodigital/>. Acesso em: 28/06/ 2012.

ESTEVES, L. R. Da tradução como amortecimento. Tradução em Revista, v. 7, p. 01-18, 2009.

Foucault, M. Verdade e Poder. In: Machado, R. (Org.). Microfísica do Poder, Rio de J aneiro: Graal, 1996. p. 1-14.

A Ordem do Discurso: aula inaugural no Collège de France, pronunciada em 2 de dezembro de 1970. São Paulo: Edições Loyola, 2011.

JEREZ, J. DE M. De la ética a la política: Hacia una nueva generación de intérpretes ciudadanos. In: BoÉRI, J. \& MAIER, C. Compromiso Social y Traducción/Interpretación. Translation/Interpreting and Social Activism. Granada: ECOS, 2007. p. 326-337.

LEWIS, B. From Babel to Dragomans: Interpreting the Middle East. Londres e Nova Iorque: Oxford University Press, 2004.

MARTINS, M. As contribuições de André Lefevere e Lawrence Venuti para a Teoria da Tradução. In: Cadernos de Letras (UFRJ) n. 27 - dez. 2010, p. 59-72.

OLIVEIRA, M. C. C. DE. A tradução e a ética da responsabilidade em períodos ditatoriais. In: Seminário do GEL, v. 56, 2008, Programação... São J osé do Rio Preto (SP): GEL, 2008. Disponível em: http:// www. gel.org. br/?mesa=22-08. Acesso em: 22/ 06/2011.

PÖCHHACKER, F. Introducing Interpreting Studies. Londres e Nova Iorque: Routledge, 2004.

. Interpreters and ideology: From 'between' to 'within'. Across Languages and Cultures, 2006, v. 7, n.2, p. 191-207. 
. Issues in interpreting studies: In: MundAY, J. (org.). The Routledge Companion to Translation Studies. Londres e Nova Iorque: Routledge, 2009, p. 128-140.

SILVA, C. \& MARTINS, M. Questões de poder e ideologia nos estudos e na prática da interpretação. 2013. 87 f. Dissertação (Mestrado) - Pontifícia Universidade Católica do Rio de J aneiro, Departamento de Letras, 2013.

TYMoczko, M. Ideology and the Position of the Translator: In What Sense is a Translator "In Between"?. In: PÉrEZ, M. C. (Ed.): Apropos of Ideology Translation Studies on Ideology - Ideologies in Translations. Manchester: St J erome Publishing, 2003, p. 181-201.

VENUTI, L. Introduction. In: The scandals of translation: towards an ethics of difference. Londres: Routledge, 1998. p. 1-7.

. "A invisibilidade do tradutor". Tradução do texto "The translator's invisibility" (Criticism. v. XXVIII, n. 2, Spring 1986, Wayne State UP, p. 179-212) por Carolina Alfaro. PaLavra (3). Rio de Janeiro: Departamento de Letras da PUC-Rio, 1995. p. 111-134. 